\title{
EVOLUCIÓN JURÍdica DEL CONTENIDO \\ DEL DEBER DE JUSTICIA EN CONTEXTOS \\ TRANSICIONALES EN COLOMBIA* \\ *
}

Nathalia Gaona Cifuentes ${ }^{(a)}$

LEGAL EVOLUTION OF THE CONCEPT OF THE DUTY OF

JUSTICE IN TRANSITIONAL CONTEXTS IN COLOMBIA

EVOLUÇÃO JURÍDICA DO CONTEÚDO DO DEVER DE JUSTIÇA

EM CONTEXTOS DE TRANSIÇÃO NA COLÔMBIA

Fecha de recepción: 10 de febrero del 2018

Fecha de aprobación: 2 de mayo del 2018

Disponible en línea: 15 de junio del 2018

Sugerencia de citación:

Gaona, N. (2018). Evolución jurídica del contenido del deber de justicia en contextos transicionales en Colombia. Razón Crítica, 5, 107-138, doi: http://dx.doi.org/10.21789/25007807.1348

\begin{abstract}
* El artículo se estructura a partir del trabajo de línea jurisprudencial denominado "Análisis dinámico de la Jurisprudencia Constitucional en torno a la obligación estatal de investigar, juzgar y sancionar todos los responsables y todos los delitos que constituyan graves violaciones a los Derechos Humanos y al Derecho Internacional Humanitario en el marco de una justicia de transición.", presentado a la Escuela Judicial Rodrigo Lara Bonilla. El anterior ejercicio investigativo fue ampliado en el marco de un desarrollo metodológico de tipo teórico y lógicoracional, a partir del análisis de fuentes secundarias de información en torno a la hipótesis o problema jurídico planteado en la línea jurisprudencial, para arribar a una postura analítica y critica del autor sobre el tema.
\end{abstract}

(a) Magíster en Derecho Internacional y Derechos Humanos con doble titulación de la Université Pierre Mendès-Grenoble y Université Catholique de Lyon

Especialista en Derecho Público. Universidad Externado de Colombia Actualmente vinculada al Ministerio de Justicia y del Derecho, Colombia https:/ / orcid.org/0000-0003-1545-4526 nathagaona29@hotmail.com 


\section{R E S U M E N}

El Estado colombiano, como sujeto de derecho internacional, es responsable de garantizar justicia mediante la investigación, el juicio y la sanción de todos los responsables por conductas configuradas a partir de graves violaciones de los Derechos Humanos y del Derecho Internacional Humanitario.

El desarrollo de modelos y medidas de transición en Colombia con miras a la terminación del conflicto armado ha pasado por distintos momentos y ha implicado diversas interpretaciones con respecto a la forma de equilibrar, por un lado, la aspiración de materializar la paz y, por el otro, la satisfacción del valor absoluto de la justicia. Las interpretaciones han pasado por posiciones maximalistas, que favorecen el deber de asegurar justicia plena, así como por aquellas posiciones que propenden por la ponderación e integración de principios y valores. El desarrollo del actual Sistema de Verdad, Justicia, Reparación y No Repetición (SIVJRNR), en el marco del acuerdo para la terminación del conflicto con la guerrilla de las FARC, ofrece la oportunidad de consolidar y equilibrar estas posiciones a fin de implementar un modelo integral de justicia transicional para nuestro país.

PALABRAS CLAVE: Deber internacional de justicia, Derechos Humanos, Derecho Internacional Humanitario, justicia transicional. 


\section{A B S T R A C T}

The Colombian State, as an international subject of law, is responsible for ensuring the access to justice through its duty to investigate, judge and sanction everyone responsible of actions considered violations of Human Rights and of the International Humanitarian Law.

In Colombia, the development of transitional models and measures intended to put an end to the armed conflict have involved different moments and interpretations around the way of balancing the aspiration of peace and the total satisfaction of justice; ranging from maximalist positions in favor of the duty of assuring full justice, to those approaches that prefer the weighting and integration of principles and values. The development of the current System of Truth, Justice, Reparation and Non-repetition (sIVJRnR, in Spanish), within the frame of the Peace Agreement with the FARC guerrilla group, provides an opportunity to consolidate and equilibrate positions with the aim of implementing a truly comprehensive model of transitional justice in our country.

KEY WORDS: International duty of justice, Human Rights, International Humanitarian Law, transitional justice.

\section{R E S U M O}

O Estado colombiano como um sujeito de direito internacional é responsável por garantir justiça por meio do dever de investigar, processar e punir todos os responsáveis e todos os comportamentos decorrentes de graves violações dos direitos humanos e do direito humanitário internacional. O desenvolvimento de modelos e medidas de transição na Colômbia para o final do conflito armado levou implícitos diferentes momentos e interpretações sobre como equilibrar o desejo de materializar a paz e a satisfação do valor absoluto da justiça, passando por posições maximalistas a favor do dever de assegurar justiça plena até aquelas que tendem pela ponderação e integração de princípios e valores. O desenvolvimento do atual Sistema de Verdade, Justiça, Reparação e não Repetição (SIVJRNR), no âmbito do acordo para acabar com o conflito com as Forças Armadas Revolucionárias da Colômbia (FARC), abre a oportunidade para consolidar e equilibrar posições, a fim de implantar um modelo verdadeiramente integral de justiça de transição para o nosso país.

PALAVRAS-CHAVE: direitos humanos, direito internacional humanitário, justiça, justiça de transição. 


\section{N T R O D U C C I Ó N}

La historia de Colombia en términos de búsqueda de la paz no es reciente, al ser una historia marcada por un fuerte conflicto armado. De hecho, desde las primeras constituciones de nuestra república se han visto reflejados los intentos por asegurar el orden y la convivencia pública, principalmente a través de figuras como la amnistía y el indulto. Si bien se han establecido excepciones y restricciones en la aplicación de estas figuras, ellas han solido adolecer de una visión integral de los derechos de las víctimas. Lo cierto es que "la forma de hacer la paz ha cambiado" (Uprimny, Sánchez, y Sánchez, 2014, p. 11).

La Constitución de 1991 además de ser el texto de la paz -pues la consagra como fin esencial del Estado- introduce el concepto de "bloque de constitucionalidad"1 como parámetro de control que garantiza la integración de los estándares internacionales de protección de los Derechos Humanos -en adelante DDHH- y el Derecho Internacional Humanitario -en adelante DIH-. A partir de la Constitución de 1991 se consolidan los deberes del Estado como garante de derechos. En materia de justicia, estos deberes se traducen en la obligación de investigar, juzgar, sancionar y reparar las graves violaciones a los DDHH y al DIH.

1 Si bien esta categoría conceptual no cuenta con unanimidad doctrinal en torno a su alcance y contenido real, jurisprudencialmente se ha entendido el bloque de constitucionalidad como al conjunto de "normas y principios que, aun cuando no aparecen en el texto constitucional, se entienden integrados a la Constitución y formalmente hacen parte de ella" (Corte Constitucional, 2017). 
Paralelamente a la Constitución de 1991, se fue gestando en la comunidad internacional la noción de justicia transicional como aquella "adaptada a sociedades que se transforman a sí mismas después de un período de violación generalizada de los derechos humanos" (Centro Internacional de Justicia Transicional -CITJ-, 2009 , p. 1), con el objetivo primordial de balancear el valor y derecho a la paz con los derechos de justicia, verdad, reparación y garantías de no repetición.

Con respecto a lo anterior, en el ámbito internacional y nacional se ha abierto el debate en torno a cuál es el alcance, contenido y posibles limitaciones de la obligación internacional de justicia en contextos de transición hacia la paz, pues estos contextos muestran una clara tensión de valores. Dicho debate adquiere especial relevancia en Colombia de cara a la implementación del reciente acuerdo de paz con la guerrilla de las FARC, producto del cual se formuló un Sistema Integral de Verdad, Justicia, Reparación y No Repetición -en adelante SIVJRNR-. El desarrollo de este sistema demuestra que se mantiene la reflexión en torno a la posibilidad de diseñar e implementar esquemas integrales de justicia transicional sin desconocer estándares internacionales, esquemas que se ajusten a la realidad y a las posibilidades fácticas y jurídicas del contexto colombiano y que a su vez morigeren las visiones maximalistas o extremistas del deber de justicia en escenarios de transformación y logren un equilibrio razonable entre los principios, valores y derechos que usualmente entran en conflicto.

El presente artículo describe la evolución jurídica, en el marco de los modelos de justicia de transición propuestos en Colombia, en torno a la menor o mayor posibilidad de modulación de la obligación internacional de investigar, juzgar y sancionar todos los posibles responsables y todos los delitos que constituyen graves violaciones de DDHH y DiH. Para esto, el artículo girará sobre el siguiente problema jurídico:

¿Es posible modular el deber internacional que tiene el Estado de investigar todos los delitos que constituyan graves violaciones a los DDHH y al DIH, asi como de juzgar y sancionar a todos sus responsables, en el marco de una justicia de transición en Colombia?

Para el abordaje de dicho interrogante se parte del análisis dinámico de la jurisprudencia en sede de revisión de 
constitucionalidad. El análisis se centra particularmente en aquellos pronunciamientos en los que la Corte Constitucional ha tenido la necesidad de establecer si determinadas disposiciones normativas expedidas, usualmente con la intención de brindar beneficios o materializar acuerdos de búsqueda de paz con grupos armados al margen de la ley, vulneran o sustituyen el deber estatal, derivado del bloque de constitucionalidad, de investigar, juzgar y sancionar todos los delitos y todos los responsables de graves violaciones a los DDHH y al DIH. Igualmente, el análisis se combina con un estudio del contexto normativo, lo cual permite un desarrollo de tipo teórico, lógico-racional y crítico en torno a la hipótesis o problema jurídico planteado con énfasis en la pertinencia actual del tema en Colombia.

Así las cosas, lo primero que se expone a continuación pretende encuadrar conceptualmente el tema principal a tratar a lo largo del artículo. Hecho esto, veremos cómo en un primer momento, después de expedida la Constitución Política de 1991, la obligación internacional de justicia tuvo un tratamiento apenas incipiente. Se describirá la evolución real de la mencionada obligación estatal y su aplicación en contextos de transición con la Ley 975 del 2005, o "Ley de Justicia y Paz", mostrando las tensiones evidentes entre la necesidad de garantizar la justicia y las medidas de alternatividad penal dispuestas en dicha ley. Hecho lo anterior, se arribará al estado actual del tema en Colombia, con abundantes y profundos desarrollos a partir de la estructuración del esquema de justicia transicional, producto del acuerdo con la guerrilla de las FARC, y que se refleja en el SIVJRNR.

\section{Aproximación a la conceptualización del deber internacional de justicia y sus enfoques en escenarios de transición}

El punto de partida del derecho internacional en materia de derechos humanos ${ }^{2}$ se ve reflejado en las

2 El cual ha tenido su más importante desarrollo en el siglo xx de cara a la necesidad de la comunidad internacional de castigar los graves crímenes cometidos durante la Segunda Guerra Mundial partiendo de postulados normativos con pretensión universal. 
obligaciones, impuestas a los Estados, de respetarlos, protegerlos y garantizarlos. En el marco de las obligaciones de garantía de los derechos de las víctimas, particularmente en materia de justicia, se ha establecido y se ha ido delineando en la comunidad internacional, el deber estatal de investigar, juzgar y sancionar todos los delitos y todos los responsables de graves violaciones a los $\mathrm{DDHH}$ y al DIH cometidas en el territorio del Estado en cualquier tiempo (Ibañez, 2017, pp. 365-366).

Así las cosas, sea derivado de las obligaciones generales de respeto y garantía de los derechos o de un recurso judicial efectivo, o sea dispuesto de manera expresa, el deber de investigar, juzgar y sancionar se encuentra inmerso en variadas declaraciones, principios, directrices e instrumentos convencionales, tanto del sistema universal de protección de Naciones Unidas ${ }^{3}$ como del sistema regional ${ }^{4}$, del ámbito de la justicia penal internacional ${ }^{5}$ y de la protección internacional humanitaria ${ }^{6}$; e, igualmente, se encuentra en las interpretaciones de los órganos autorizados de tales instrumentos.

Aunque se ha debatido mucho sobre el contenido y el alcance del deber de investigar, juzgar y sancionar, no es posible aún delimitar con certeza cada una de las categorías incluidas en lo que se denomina graves violaciones a los DDHH y al DIH. No obstante, lo que sí es claro a partir de los distintos mecanismos e instrumentos internacionales es que el mencionado deber -entendido como un principio que debe ser realizado en la mayor medida posible-se

3 Vinculados al deber de respeto y garantía de derechos y de acceso a un recurso judicial efectivo, en el sistema universal se pueden mencionar la Declaración Universal de los Derechos Humanos, el Pacto Internacional de Derechos Civiles y Políticos. De manera expresa, el deber de investigar, juzgar y sancionar se encuentra en la Convención para la prevención y sanción del delito de Genocidio; la Convención internacional sobre la represión y el castigo el crimen de Apartheid; la Convención contra la tortura y otros tratos o penas crueles, inhumanos o degradantes; la Convención internacional para la protección de todas las personas contra las desapariciones forzadas. Igualmente, el derecho a la justicia se recoge en los principios y directrices internacionales sobre la lucha contra la impunidad y en los principios y directrices básicos sobre el derecho a de las víctimas de violaciones de las normas internacionales de DDHH y de violaciones graves del DiH.

4 Vinculado al deber de respeto y garantía de derechos y de acceso a un recurso judicial efectivo, se puede mencionar el sistema regional la Convención Americana de Derechos Humanos.

5 De manera expresa, frente a los crímenes internacionales de competencia de la Corte Penal Internacional, el preámbulo del Estatuto de Roma.

6 De manera expresa, los Convenios de Ginebra de 1949. 
circunscribe al ámbito del ejercicio diligente de la acción penal dirigida a esclarecer, perseguir y castigar de manera proporcional a todos los responsables de tales crímenes.

En virtud del bloque de constitucionalidad, el cual se integra a la Constitución Política de Colombia de 1991 y se circunscribe a los tratados en materia de derechos humanos aprobados y ratificados por Colombia, así como a la doctrina autorizada elaborada por los tribunales internacionales u órganos de control de tales tratados, el Estado colombiano es responsable de investigar, juzgar y sancionar todos los delitos y todos los responsables de graves violaciones a los DDHH y al DiH que ocurren en territorio nacional.

Ahora bien, el cumplimiento de dicho deber de justicia de manera plena por parte del Estado frente a todos los graves crímenes y todos sus responsables lleva a encrucijadas al momento de enfrentar y superar situaciones de violaciones reiteradas a los DDHH y al DIH, usualmente provocadas por gobiernos con fuerte tendencia dictatorial o por conflictos armados internos, como en el caso colombiano. Las experiencias en el mundo de tránsito y reafirmación del Estado de Derecho, la democracia, la vigencia de derechos y el restablecimiento de la paz, desde un período incipiente inmediatamente posterior a la Segunda Guerra Mundial (Ibañez, 2017, p. 123) hasta nuestros días, han permitido desarrollar, en el marco de la comunidad internacional, una concepción de justicia denominada transicional, relacionada directamente con contextos de transformaciones profundas en un Estado ${ }^{7}$.

Sin pretender desarrollar un análisis sobre la concepción de justicia transicional, para efectos del objeto principal del presente artículo se comparte aquella descripción, sencilla pero suficientemente ilustrativa, que sobre la justicia transicional presenta Angélika Rettberg como "[...] el tipo de arreglos institucionales y extrajudiciales que facilitan y permiten la transición de un régimen

7 Todos estos elementos son recogidos en la definición de justicia transicional presentada por el Centro Internacional de Justicia Transicional en los siguientes términos: "Cada vez más, los académicos adoptan la definición elaborada por el ICTJ: "La justicia transicional es una respuesta a las violaciones sistemáticas o generalizadas de los derechos humanos. Busca el reconocimiento de las víctimas y promover posibilidades de paz, reconciliación y democracia. La Justicia transicional no es una forma especial de justicia, sino una justicia adaptada a sociedades en proceso de transformación después de un periodo agudo de abusos de los derechos humanos. En algunos casos, estas transformaciones suceden sorpresivamente; en otros, transcurren durante muchas décadas" (Olsen, Payne, y Reiter, 2016, p. 33). 
autoritario a una democracia o de una situación de guerra a una de paz” (Rettberg, 2005, p. 1). Esta definición doctrinal coincide en sus elementos con la elaborada institucionalmente por la Organización de Naciones Unidas ${ }^{8}$.

Dichos arreglos judiciales y extrajudiciales, propios de la justicia transicional, involucran los más variados mecanismos: “[...] el enjuiciamiento de personas, el resarcimiento, la búsqueda de la verdad, la reforma institucional, la investigación de antecedentes y las destituciones" (ONU, 2011). Estos mecanismos se dirigen al cumplimiento, no solo de la finalidad de reconciliación y paz, sino de la protección de los derechos de las víctimas a la verdad, la justicia, la reparación y las garantías de no repetición.

Es así como, en función del mecanismo o los mecanismos transicionales a los que se les otorgue preponderancia, se han venido planteando desde la academia los denominados enfoques de justicia transicional. De manera general se plantea un enfoque maximalista, el cual privilegia los juicios penales ${ }^{9}$; un enfoque minimalista, ligado a la utilización prevalente de la figura de la amnistía; y un enfoque holístico que pretenden integrar distintos mecanismos para hacer frente a los retos de la transición (Olsen, Payne y Reiter, 2016, p. 218). Uprimny, Sánchez y Sánchez (2014, p. 93) se refieren a los enfoques maximalista, minimalista, moderado y holístico, en el marco de los tipos o modelos ideales de transición, así:

Estos tipos ideales de transición pueden a su vez ser relacionados con distintos enfoques de justicia transicional. Siguiendo a Olsen, Payne y Reiter (2010), es posible identificar cuatro grandes aproximaciones teóricas en este campo, las cuales se definen en atención al tipo de mecanismo que privilegian para avanzar hacia la consolidación de la democracia y los derechos humanos en un contexto transicional. El primero es un enfoque maximalista que reivindica la justicia retributiva y, por tanto, los juicios penales como el instrumento por

8 La Organización de Naciones Unidas indica que la justicia transicional abarca "toda la variedad de procesos y mecanismos asociados con los intentos de una sociedad por resolver los problemas derivados de un pasado de abusos a gran escala, a fin de que los responsables rindan cuentas de sus actos, servir a la justicia y lograr la reconciliación" (ONU, 2014).

9 Barbosa F. se refiere al "maximalismo carcelario" (Barbosa, 2017, p. 183). 
excelencia para una transición exitosa. De acuerdo con esta aproximación, la realización de juicios penales no solo es un imperativo legal, sino que es necesaria para disuadir la comisión de futuras violaciones, afianzar la vigencia del derecho y evitar la justicia privada. En contraste, el segundo, el enfoque minimalista, privilegia la concesión de amnistías como un mecanismo para garantizar la estabilidad necesaria a fin de avanzar en la consecución de los fines de las transiciones. El tercero, el enfoque moderado, cuya piedra angular es la justicia restaurativa, exalta el papel de mecanismos extrajudiciales de rendición de cuentas como las comisiones de la verdad, pues reconoce que la justicia retributiva puede obstaculizar la transición, pero al mismo tiempo advierte la necesidad de que exista algún tipo de atribución de responsabilidad por las violaciones de los derechos humanos que pretenden ser superadas. Finalmente, el cuarto es un enfoque holístico que promueve la articulación de los distintos mecanismos judiciales -juicios penales y amnistías-y no judiciales -comisiones de la verdad y programas administrativos de reparación-, bajo la consideración de que ningún instrumento es suficiente por sí mismo para satisfacer las complejas demandas que se plantean en un proceso de transición.

Resulta así que las experiencias transicionales normalmente han transitado por alguno de los enfoques antedichos o por una combinación de aquellos. Lo cierto es que el holístico resulta ser el enfoque que ha venido adquiriendo mayor fuerza por su capacidad de mitigar los principales defectos que presentan los restantes.

En lo que se refiere al deber de investigar, juzgar y sancionar todos los delitos y todos los responsables de graves violaciones a los DDHн y al DIH, la crítica al enfoque maximalista se ha hecho evidente al resaltar que la pretensión de su satisfacción irrestricta es compleja y enfrenta obstáculos en escenarios de transición. Principios de igual categoría como la paz, la verdad o la reparación deben ser igualmente garantizados; pero limitaciones eminentemente materiales, económicas o logísticas, e incluso válidas aspiraciones de tipo político propias de los procesos de negociaciones de paz dificultan en grado sumo la garantía plena y absoluta del mencionado deber internacional (Torres, 2015, p. 100). 
En esa medida, existe un debate constante dirigido a determinar cuál es el alcance, contenido y posibles limitaciones o modulaciones al deber y principio de investigar, juzgar y sancionar todos los delitos y todos los responsables de graves violaciones a los DDHH y al DIH en contextos de transición hacia la paz. Las experiencias en Colombia han permitido recorrer, normativa y jurisprudencialmente, desde posiciones maximalistas a favor del deber de asegurar justicia plena hasta aquellas que propenden por la ponderación e integración de principios, valores e intereses legítimos. Es este el tema en el que se concentrará el artículo a continuación.

\section{Los inicios del deber internacional de justicia en contextos de paz en Colombia}

Los esfuerzos más próximos a la expedición de la Constitución de 1991 para materializar acuerdos de restablecimiento del orden y la convivencia social giraron en torno a las figuras de amnistía e indulto bajo estados de excepción ${ }^{10}$, que fueron aplicadas normalmente a delitos políticos y conexos, pero que excluyeron a los que se denominaron, en su género, "atroces"11. Así, con posterioridad a 1991, fueron expedidas varias leyes y decretos legislativos al amparo de facultades de conmoción interior que otorgaron este tipo de beneficios y delimitaron las exclusiones, producto también de la interpretación constitucional en su momento.

10 Durante la segunda mitad del siglo xx, y antes de la proclamación de la Constitución Política en 1991, Colombia atravesó por varios procesos de diálogo y sometimiento de grupos insurgentes. Uno de ellos fue el sometimiento de las guerrillas liberales durante el gobierno del general Rojas Pinilla. En 1974 se dieron los diálogos de paz entre el gobierno de Alfonso López Michelsen y el ELn. En 1984 el presidente Belisario Betancur instauró los diálogos de paz con las FARC y con el M-19 y EPL. En 1986 el gobierno de Virgilio Barco firmó los acuerdos de paz con el M-19 y el EPL; adicionalmente se realizaron acercamientos con las FARC y el ELN. En 1990 el M-19 entrega las armas y el gobierno de Cesar Gaviria inicia diálogos con las FARC, el ELN y el EPL. Generalmente dichos procesos estuvieron acompañados de mecanismos legales que buscaban la amnistía o el indulto de los combatientes. De los procesos mencionados, cabe resaltar la amnistía proclamada por Rojas Pinilla a los combatientes de las guerrillas liberales. Otros mecanismos jurídicos fueron la Ley 35 de 1982 (amnistía por delitos políticos), la Ley 77 de 1989 (la cual facultó al Presidente de la República para conceder indultos) y la Ley 7 de 1992 (la cual estableció el principio de favorabilidad y el beneficio de la cosa juzgada para los guerrilleros beneficiados con indultos y amnistía).

11 Entre estos, los delitos de secuestro; genocidio; homicidio cometido fuera de combate, con sevicia o colocando a la víctima en estado de indefensión; actos de ferocidad y barbarie; interpretados jurisprudencialmente como graves infracciones al DIH. 
A pesar del carácter vinculante del bloque de constitucionalidad a partir de 1991, ni en las disposiciones normativas ni en los fallos de constitucionalidad de la época se encuentran menciones expresas a (i) el deber estatal de investigar, juzgar y sancionar las graves violaciones a los DDHH y al DIH o (ii) al concepto jurídico de justicia transicional, probablemente porque tales nociones jurídicas estaban aún en pleno desarrollo a nivel internacional. La mención más cercana, aunque somera, se encuentra en la sentencia de la Corte Constitucional C-171 de 1993, que declara inexequible el Decreto Legislativo 264 del mismo año ${ }^{12}$ por ir en contra del valor de justicia, haciendo referencia al "compromiso solemne con la comunidad internacional de investigar, procesar, juzgar y castigar a los delincuentes" (cc, 1993).

A partir de la consolidación del bloque de constitucionalidad, en la jurisprudencia de la Corte Constitucional comienza a tratarse in extenso el tema de las obligaciones derivadas del mismo. Con ello se ampliaron las categorías de las típicas violaciones a los ddhh como excepciones a la aplicación de figuras de amnistía e indulto13 en sentencias como la C-695 del 2002 y la C-928 de 1995. Esta postura se ha mantenido más o menos estable en la jurisprudencia constitucional actual.

\section{Evolución del deber internacional de justicia en contextos transicionales en Colombia.}

\section{Reconocimiento del principio general de justicia transicional. La justicia y la paz como principios ponderables.}

El 25 de julio del 2005, por iniciativa del Gobierno, fue expedida la Ley 975, conocida como "Ley de Justicia y Paz". Su objetivo era servir de marco jurídico para las negociaciones de paz entre el Gobierno y los grupos paramilitares. Lo novedoso de esta ley es que se refería

\footnotetext{
12 Por el cual se expiden normas sobre concesión de beneficios por colaboración con la justicia.

13 En el ámbito interamericano, predominaba la tesis de la CIDH expuesta en el 2001, en la sentencia Barrios Altos contra Perú, acerca de la prohibición de amnistías e indultos para graves violaciones de DDHH.
} 
de manera expresa a los derechos de las víctimas a la verdad, justicia, reparación y no repetición, reconocidos internacionalmente.

Es necesario advertir que la Ley 975 del 2005 no ha sido una ley ampliamente aceptada en la sociedad colombiana. De hecho, fue demandada por inconstitucional al considerarse un "sistema de impunidad"14 por varias organizaciones dedicadas a la defensa de los DDHH y al análisis de situaciones de transición ${ }^{15}$. El debate giró entonces en torno a la consideración de que el esquema de alternatividad penal dispuesto en la Ley, para actores armados responsables de crímenes atroces, resultaba ser una limitación desproporcionada a los derechos de las víctimas y, en particular, al deber de investigar, juzgar y sancionar los graves crímenes contra los DDHH y el DIH. Es decir, la Ley garantizaba un sistema de impunidad e inobservancia de los estándares internacionales.

Se trataba de un asunto con escasos antecedentes en Colombia $^{16}$. En su momento, la Corte Constitucional, a través de la sentencia C-370 del 2006 ${ }^{17}$, decide aceptar el "principio general de la justicia transicional para Colombia" (Uprimny, Saffon, Botero, y Restrepo, 2006, p. 226), así como la importancia del valor y derecho a la paz. Así las cosas, en la más alta sede judicial, si bien se reconoce el deber internacional de investigar, procesar y sancionar los responsables de graves violaciones a los DDHH $^{18}$, se admite también la posibilidad de establecer ciertas restricciones o alternativas de modulación con el fin de promover, no solamente la búsqueda de la paz en momentos de transición, sino la garantía de otros derechos de las víctimas, como el de obtener verdad plena, reparación integral y garantías de no repetición.

De esta manera, se empieza a entender el asunto como un conflicto de principios o valores a ser realizados en la mayor medida

\footnotetext{
14 Demanda presentada por el director de la Comisión Colombiana de Juristas, Gustavo Gallón Giraldo y otros.

15 El Centro Internacional por la Justicia Transicional, la Comisión Internacional de Juristas, entre otros.

16 En efecto, la propia Corte Constitucional, al realizar el análisis constitucional a través de la sentencia C-370 del 2006, afirma que “[...], cabe advertir que el problema novedoso que plantea la Ley 975 de 2005 es el de cómo ponderar la paz. La cuestión es compleja no solo por su novedad sino por la enorme trascendencia que la Constitución de 1991 le asignó a la paz".

17 Con ponencia del magistrado Álvaro Tafur Galvis y otros.

18 Si bien se reconoce como un deber emanado de distintos instrumentos y jurisprudencia internacional, la Corte, en dicha ocasión, no fue explícita acerca de la pertenencia de dicha obligación internacional al bloque de constitucionalidad.
} 
posible; valores que deben ser evaluados en cada caso concreto. En ese sentido, la Corte se apoya en un ejercicio de ponderación, el cual incluye, no solamente los aspectos punitivos de la Ley 975, sino los demás derechos de las víctimas. Así, la Corte alerta implícitamente sobre la necesidad de diseñar estrategias integrales de búsqueda de la paz que contemplen todos los componentes de la justicia transicional ${ }^{19}$, y que no se enmarquen exclusivamente en la fase punitiva.

En consecuencia, en relación con el instrumento de justicia transicional denominado por la Ley 975 pena alternativa ${ }^{20}$-que consiste en "generosas rebajas de pena a los actores armados que hayan cometido crímenes atroces con miras a promover su desmovilización” (Uprimny, Saffon, Botero, y Restrepo , 2006, p. 266)-, el Tribunal Constitucional concluyó que, a pesar de su levedad, no vulneraba el valor de la justicia, representado en el deber de investigar, procesar y sancionar las graves violaciones a los DDHH y al DiH ${ }^{21}$. No obstante, a fin de lograr un verdadero equilibrio entre el conjunto de derechos de las víctimas, la sentencia C-370 del 2006 establece mecanismos que permiten endurecer las obligaciones de verdad y reparación para acceder a los beneficios punitivos: revocar la pena alternativa en caso de incumplimiento de tales obligaciones ${ }^{22}$, garantizar el cumplimiento efectivo de la pena alternativa $^{23}$, entre otros.

19 "Las iniciativas relacionadas con la justicia transicional fomentan la rendición de cuentas, refuerzan el respeto por los derechos humanos y son cruciales para generar los fuertes niveles de confianza cívica que son necesarios para impulsar la reforma del estado de derecho, el desarrollo económico y la gobernanza democrática. Tales iniciativas pueden comprender mecanismos tanto judiciales como extrajudiciales, incluidos el enjuiciamiento de personas, el resarcimiento, la búsqueda de la verdad, la reforma institucional, la investigación de antecedentes y las destituciones" (oNU, 2011).

20 Más que de una pena alternativa propiamente dicha, se trata realmente de un beneficio o rebaja punitiva, tal como lo indica la Corte Constitucional en la sentencia C-370 de 2006 “[...] De las anteriores disposiciones se derivan los elementos esenciales de la denominada pena alternativa, tal como la contempla la ley, que por su importancia conviene sistematizar, a partir de lo dicho en el apartado 6.2.1.4.2., así:

(i) Es un beneficio punitivo que conlleva suspensión condicional de la ejecución de la pena determinada en la respectiva sentencia, el cual responde a características y propósitos específicos".

21 Como sentencias de reiteración de principio, se cuenta con la C-530 y la C-575 del 2006.

22 En tal caso, se debe cumplir la pena principal que se mantiene en la sentencia condenatoria.

23 Para lo cual se descarta la posibilidad de descontar tiempo de privación de libertad en establecimientos sin vigilancia penitenciaria. 


\section{De la evidente tensión entre la necesidad de garantía de justicia y medidas aisladas de alternatividad penal.}

Entre el 2007 y el 2012, en el escenario jurídico del país se presenció una pugna de principios. Por un lado, el gobierno nacional intentaba definir la situación jurídica de los desmovilizados a través de distintas posibilidades normativas; por otro, la Corte Constitucional se encontraba en un período difuso en el cual, si bien predominó la premisa maximalista de "investigar todos los hechos y procesar todos los excombatientes” (Uprimny, Sánchez, y Sánchez, 2014, p. 197), también existía la postura, aún tímida, de ponderación y moderación de tal premisa institucional.

El debate comienza en el 2007 con ocasión del fallo de la Corte Suprema de Justicia -en adelante CSJ- con radicado $\mathrm{N}^{\circ} 26945^{[24]}$, que consideró que el concierto para delinquir agravado (inciso 2, art. $340 \mathrm{CP})^{25}$ cometido por los grupos paramilitares o de autodefensa no era un delito político pasible de amnistía, indulto o figuras con consecuencias similares. De hecho, el fallo considera dicho delito como de lesa humanidad ${ }^{26}$. Se expide entonces la Ley 1312 del 2009, que buscó brindar una solución jurídica a los desmovilizados rasos, no postulados a la Ley 975 y afectados por el fallo de la CSJ, a través de la posibilidad de aplicar el principio de oportunidad por conductas relacionadas con su pertenencia a la organización criminal.

En un escenario de litigio más complejo, la ley mencionada fue demandada, y fue declarada inexequible por la sentencia C-936 del $2010^{27}$ al considerar que la posibilidad eventual de suspender, interrumpir o renunciar a la acción penal frente a graves crímenes vulneraba el deber general de investigar, juzgar y sancionar las violaciones de los DDHH y el DIH. Tal como lo manifestó el magistrado Juan Carlos Henao en salvamento de voto, se considera que el fallo representó un giro en la interpretación de las subreglas

24 El fallo tuvo como magistrados ponentes al doctor Yesid Ramírez Bastidas y al doctor Julio Enrique Socha Salamanca.

25 El inciso incluye conductas que pueden configurar graves violaciones a los DDHH y al DIH.

26 En razón a que el concierto agravadol se da para cometer conductas que pueden

configurar graves violaciones a los DDHн y al DIH.

27 Con ponencia del magistrado Jorge Iván Palacio P. 
fijadas en la C-370 del 2006. A pesar de los antecedentes que permitían concluir que la Ley 1312 había sido expedida en el marco de la desmovilización -y que por ende compartía, por lo menos de manera parcial, elementos transicionales-, la Corte decide analizar el caso como un asunto de política criminal ordinario, descartando la ponderación como método de análisis. Así las cosas, si bien se parte de una de las premisas de la C-370 del 2006, esto es, el deber general de investigar, procesar y sancionar a los responsables de graves violaciones a los DDHH y el DIH, también se descarta, en la valoración de los cargos, el principio general de justicia transicional y sus posibilidades de modulación ${ }^{28}$.

Debido a este fallo, y ante el cierre de posibilidades para definir la situación jurídica de desmovilizados rasos, se expide a instancias del gobierno nacional la Ley 1424 del 2010 que, sin renunciar a la judicialización, permite la suspensión de órdenes de captura y de la ejecución de la pena, de manera condicionada, por delitos relacionados con la pertenencia a la organización criminal, entre ellos, el concierto para delinquir agravado. En sede de constitucionalidad, a través de la sentencia C-711 del 2011²9, no se encontró mayor dificultad para validar la exequibilidad de las posibilidades jurídicas contempladas en Ley 1424, en el entendido de que los beneficios otorgados, esto es, la suspensión de órdenes de captura y de la ejecución de la pena, no implicaban renunciar a la acción penal y, por ende, se cumplía con el deber de investigación y juzgamiento de conductas que constituían graves violaciones a los DDHH y el DIH. No obstante, los cuatro salvamentos de voto ${ }^{30}$ presentados consideraron que tales beneficios punitivos resultaban improcedentes ante la gravedad de los delitos y, por ende, el fallo era a todas luces flexible frente al deber de justicia con respecto a graves violaciones de los DDHH y el DIH.

28 Este giro de interpretación jurisprudencial hizo que se contara con un fallo absolutamente dividido - con cuatro salvamentos de voto de los magistrados Juan Carlos Henao, Mauricio González C., Jorge Pretelt C. y Humberto Sierra Porto-, quienes sustentaron su disenso en que no se valoraron las normas acusadas en un contexto de justicia transicional, lo cual habría permitido por lo menos condicionar la exequibilidad de la norma.

29 Con ponencia del magistrado Nilson Pinilla P.

30 Magistrados María Victoria Calle C., Luis E. Vargas S., Jorge I. Palacio P., y Gabriel E. Mendoza M. 
Finalmente, la visión maximalista del deber internacional de justicia, durante la presente etapa, se reafirma con ocasión de la sentencia C-715 del 2012 ${ }^{31}$, que declara inexequible la posibilidad, establecida en la Ley 1448 del $2011^{32}$, de aplicar el principio de oportunidad a delitos relacionados con la ilegalidad de títulos o el despojo de las tierras. Si bien se reconoce la especialidad, y ciertas posibilidades de excepción en los regímenes de transición, se descarta el principio de oportunidad en tales casos por considerarlo violatorio del deber de investigar, juzgar y sancionar a los responsables de graves delitos contra los DDHH y el DIH, y por considerar que no se cuenta con una estrategia integral de investigación de tales delitos en un escenario de transición. Con esta última conclusión la Corte insinuaba que, de contarse con una estrategia integral de justicia transicional, un juicio de constitucionalidad de medidas de alternatividad penal o de modulación del deber general de justicia podría ser superado.

No obstante, atendiendo a lo manifestado por el magistrado Gabriel E. Mendoza M. en su salvamento de voto en esta sentencia, se considera que al declarar la inexequibilidad pura y simple se desaprovechó la posibilidad de aplicar el principio de oportunidad a personas con un grado de participación menor en los procesos de despojo. A partir de este momento se introduce en el debate la reflexión sobre la posibilidad de realizar diferenciaciones según el grado de responsabilidad o participación en estos graves crímenes.

\section{Hacia sistemas integrales de justicia transicional}

Ante los exiguos resultados de la Ley 975 del 2005 (Uprimny, Sánchez, y Sánchez, 2014, p. 103), las férreas interpretaciones judiciales, la pérdida de vigor del discurso en torno a la seguridad democrática, así como la debilidad política y militar de la guerrilla de las FARC (Gómez, 2014), en marzo del 2012 se inicia una fase de

31 En esta ocasión actúa nuevamente como demandante el director de la Comisión Colombiana de Juristas, Gustavo Gallón Giraldo. Sus intervenciones fueron apoyadas por varias organizaciones de víctimas y campesinos.

32 Por la cual se dictan medidas de atención, asistencia y reparación integral a las víctimas del conflicto armado interno y se dictan otras disposiciones. 
diálogos exploratorios entre el gobierno de Juan Manuel Santos y esta guerrilla en búsqueda de la firma de un acuerdo para la terminación del conflicto. Paralelamente, se estructura el sustento jurídico del proceso negocial a través del Acto Legislativo 01 de 31 de julio del 2012, o Marco Jurídico para la Paz, mediante el cual la justicia transicional adquiere fuerza constitucional; fuerza de la cual carecieron las disposiciones con rango legal antes analizadas.

Es así como, en el marco del acuerdo con la guerrilla de las FARC, se retoma con renovado vigor una tendencia a la modulación de la obligación internacional de investigar, juzgar y sancionar todos los responsables y todos los delitos que constituyen graves violaciones a los DDHH y al DiH con el fin de conciliar el derecho y valor fundamental de consolidar la paz con los demás derechos de las víctimas. Se constitucionaliza así la posibilidad de acudir a instrumentos tanto judiciales como extrajudiciales, incluyendo criterios de priorización y selección que permitan escoger los delitos más graves y representativos a investigar ${ }^{33}$ y los máximos responsables a judicializar. Además, se ofrecen posibilidades para la extinción de la acción penal, alternativas de sanción y de cumplimiento o suspensión de la misma.

En esta nueva etapa, el poder judicial en Colombia, representado por la Corte Constitucional, decide apoyar la iniciativa política frente a la evidente polémica que dominaba el ambiente ${ }^{34}$. Es así como, en la sentencia C-579 del 2013, se acude al método del juicio por sustitución de la Constitución y, en dicho marco, a la metodología de la ponderación entre todos los principios en juego, tal como lo estableció la C-370 del 2006. Pero esta vez se adopta la visión de un "sistema complejo de justicia transicional", y no un sistema constituido por disposiciones jurídicas dispersas, con lo cual se reivindica en cierta medida el concepto de estrategia de justicia transicional, echado de menos en revisiones anteriores.

33 Crímenes de lesa humanidad, genocidio, o crímenes de guerra cometidos de manera sistemática.

34 Ténganse en cuenta las variadas y divergentes intervenciones presentadas durante el trámite de la acción de constitucionalidad contra el Acto Legislativo 01 del 2012 y los dos salvamentos de voto emitidos. La mayoría de conceptos de expertos recibidos coinciden con la exequibilidad, mientras que la academia universitaria se encuentra dividida y varias organizaciones de derechos humanos apoyan los cargos de la demanda, frente a un gobierno que defiende la reforma, al considerarla como una estrategia de justicia transicional. 
La Corte empieza por revisar, a partir de una interpretación histórica y sistemática, la conceptualización y subreglas jurisprudenciales en la materia desde la C-370 del 2006, y reconoce como pilar fundamental de la Constitución, y premisa mayor en el juicio de sustitución, el deber de respetar, proteger y garantizar los derechos de las víctimas y, dentro de estos, el derecho a la justiciacompuesto por el deber de investigar, juzgar y dado el caso sancionar las graves violaciones a los DDHH y al DIH. Como premisa menor, se valora la búsqueda de una paz estable y duradera como objetivo del Acto Legislativo, lo que permite adoptar medidas de justicia transicional; entre ellas, usar los instrumentos de clasificación, orden de investigación (priorización) y selección de casos a ser judicializados.

Vale la pena mencionar que, en el contexto interamericano, en octubre del 2012 la Corte Interamericana de Derechos Humanos -COIDH- emitió sentencia en el caso El Mozote ${ }^{35}$. Este caso es para muchos, junto al voto concurrente del Juez Diego García-Sayán ${ }^{36}$, la antesala a un posible giro o modulación jurisprudencial del alto tribunal regional que lo distancia de la línea pacífica que había mantenido, la cual tiende a prohibir de manera absoluta figuras como la amnistía, o figuras con efectos similares, frente a graves violaciones de DDHH por violar el deber de investigación, judicialización y sanción.

En este nuevo caso, la COIDH reconoce encontrarse ante un contexto distinto a los anteriormente decididos, un contexto enmarcado en un acuerdo de búsqueda de la paz. Por esta razón la Corte sostiene que el análisis debe, no solo partir de la Convención Americana sobre Derechos Humanos, sino atender de manera armónica las disposiciones especiales del protocolo in Adicional a los Convenios de Ginebra de $1949^{37}$ y del acuerdo de paz celebrado. Esto podría, eventualmente, permitir arribar a decisiones moduladas en otros casos. El voto concurrente del Juez García-Sayán se permite ir

35 Providencia que fue citada por la Corte en los fundamentos de la sentencia C-579 del 2013.

$36 \mathrm{Al}$ cual adhirieron cuatro integrantes de la COIDH.

37 Que en su artículo 6.5 indica que "[a] la cesación de las hostilidades, las autoridades en el poder procurarán conceder la amnistía más amplia posible a las personas que hayan tomado parte en el conflicto armado o que se encuentren privadas de libertad, internadas o detenidas por motivos relacionados con el conflicto armado". 
más allá, al reconocer las posibles tensiones entre la paz y la justicia, así como la necesidad de realizar un juicio de ponderación entre las distintas alternativas admisibles, tales como el procesamiento prioritario, las penas alternativas o suspendidas o, incluso, amnistías -siempre que se garanticen estándares mínimos frente a los demás derechos de las víctimas-.

Todo lo anterior permitió que en el marco jurídico colombiano se ampliara el ámbito de modulación a través de distintas alternativas interpretativas del deber general de investigar, juzgar y sancionar todas las graves violaciones a los DDHH y al DIH y todos los posibles responsables, a partir de las siguientes conclusiones ofrecidas por el Alto Tribunal Constitucional en la sentencia C-579 del 2013 ${ }^{38}$ :

- Se concluye que las categorías de genocidio, crímenes de lesa humanidad y de guerra cometidos de manera sistemática, subsumen las graves violaciones a los DDHH cometidas en el marco de un conflicto armado. Por tal razón, la estrategia de centrar la investigación en dichas categorías no desconoce la obligación internacional de investigar todas las graves violaciones a los DDHH y al DIH.

- Se acepta que se seleccionen para imputación y judicialización únicamente a quienes sean considerados, desde una perspectiva amplia, máximos responsables de tales categorías criminales. Esto se hace con el fin de centrar esfuerzos en establecer y atacar fenómenos y patrones macrocriminales (López, 2012), lo cual permite mejorar el impacto y la efectividad.

- Se acepta la posibilidad de no judicializar ni sancionar a todos los responsables de genocidio, o crímenes de lesa humanidad y de guerra cometidos de manera sistemática, al permitir la renuncia condicionada a la acción penal en relación con personas que, sin ser máximos responsables, hayan cometido tales crímenes.

$38 \mathrm{Al}$ igual que en las aclaraciones de voto de María Victoria Calle C., Luis Ernesto Vargas S. y Alberto Rojas Ríos., se considera que en la C-579 del 2013 la Corte se excedió en el juicio de sustitución, entrando en el análisis y determinación de detalles que podrían llegar a constituir injerencia en la facultad del legislador que desarrollará los componentes del Acto Legislativo. 
- Se acepta la suspensión condicional de la totalidad de la pena para los casos no seleccionados y, con respecto a los casos seleccionados, se acepta tal posibilidad siempre que el beneficio no se aplique a la totalidad de la pena.

- Se admiten las penas alternativas, extrajudiciales y las modalidades especiales de cumplimiento de la pena, incluso para los casos seleccionados.

- Con el fin de salvaguardar en mayor medida los derechos de las víctimas, la Corte fija criterios adicionales -como el de garantizar la transparencia en el proceso de priorización y selección, así como recursos efectivos para impugnar las decisiones al respecto; la debida diligencia de las investigaciones que se emprendan; la reparación integral; entre otros-.

A partir de entonces, las disposiciones emitidas en la Sentencia C-579 del 2013 han representado una referencia esencial en el desarrollo institucional del SIVJRNR, en particular en su componente de justicia ${ }^{39}$, hoy expresado en el Acto Legislativo 01 del $2017^{40} \mathrm{y}$ el proyecto de Ley Estatutaria 008 del 2017-Senado y 016 del 2017-Cámara "Estatutaria de la Administración de Justicia en la Jurisdicción Especial para la Paz"- ${ }^{41}$.

Igualmente, la síntesis de la Sentencia C-674 del 2017, conocida mediante comunicado de prensa el 14 de noviembre del $2017^{42}$, resultó vital para concretar ciertos aspectos ${ }^{43}$ del trámite

39 El 11 de septiembre del 2015 las delegaciones de paz llegan a un acuerdo parcial sobre justicia transicional referente al punto de víctimas, el cual contenía la creación del Sistema Integral de Verdad, Justicia, Reparación y no Repetición. Igualmente, se estipulan los principios de la Jurisdicción Especial para la Paz. Producto del proceso seguido al "no" en el plebiscito, el 24 de noviembre del 2016 se firma el acuerdo del Teatro Colón, denominado "Acuerdo Final para la Terminación del Conflicto y la Construcción de una Paz estable y Duradera”, y se termina el proceso de negociación el 29 de noviembre del 2016, cuando el Congreso de Colombia refrenda el acuerdo. 40 Por medio del cual se crea un título de disposiciones transitorias de la Constitución para la terminación del conflicto armado y la construcción de una paz estable y duradera y se dictan otras disposiciones.

41 Proyecto conciliado. Gaceta N. . 1108 del 2017.

42 Comunicado N. ${ }^{\circ} 55$ del 14 de noviembre del 2017, expediente RPZ-003-Sentencia C-674 del 2017, Corte Constitucional. A la fecha del presente artículo, no se conoce el fallo en su totalidad.

43 Como el tema de la participación en política de miembros de las FARC, la cual se avala en principio. Esto otorga a la JEP la competencia de determinar la compatibilidad, con la participación en política, de las sanciones que se impongan a los excombatientes. Considérese también el tema de la competencia personal de la JEP en relación con terceros civiles y agentes estatales diferentes a miembros de la Fuerza Pública, que se estableció como voluntaria. 
legislativo respecto al proyecto de Ley Estatutaria de la Jurisdicción Especial para la Paz -en adelante JEP-. En esta ocasión la Corte Constitucional declaró exequible el SIVJRnR, sin perjuicio de la inexequibilidad de algunos apartes normativos ${ }^{44} \mathrm{y}$ de ciertas precisiones frente a otros. Siguiendo los postulados establecidos desde la C-370 del 2006, complementados por la C-579 del 2013, el alto tribunal acude a la metodología del juicio de sustitución de la Constitución y a la ponderación entre los distintos valores en juego, en la C-674 del 2017.

Si bien la Corte identifica como eje definitorio de la Constitución el deber estatal de investigar, juzgar y sancionar las graves violaciones de DDHH y las infracciones al DIH, confirma también que los criterios de priorización y selección son inherentes a un sistema de justicia transicional. El argumento gira en torno a la razonable medida en que el deber internacional de justicia será cumplido, manifestando que:

[...] El rigor del juicio de sustitución de las reformas adoptadas por el Congreso en contextos de transición dirigidos a su realización, debe atenuarse, aminorarse o moderarse de manera que sea posible, con ese propósito, introducir modificaciones -incluso profundas- al ordenamiento constitucional [...] la resistencia al cambio que detentan las normas constitucionales en pro de la garantía de la integridad del orden constitucional que esta [la Corte] debe guardar, se flexibiliza con una dosis de adaptabilidad que asegure la validez de reformas más amplias que las que pueden darse en tiempos ordinarios [...]. (CC, 2017)

A pesar de la flexibilidad permitida con el fin de asegurar la mayor garantía de los derechos de las víctimas, la Corte defiende lo que denomina un "Régimen de Condicionalidad", que se entiende como el conjunto de supuestos que deben ser reunidos o cumplidos por las personas que se acojan al sistema. Así que, en caso de

\footnotetext{
44 Entre otros, el relativo a las reglas especiales de tutela; la posibilidad de que la JEP realizara cualquier tipo de verificación de información que comprometa a un expresidente de la república; la intervención de los juristas extranjeros en los debates de las salas o secciones de las instancias de la JEP; las disposiciones relativas a las reglas ante conflictos de competencia y necesidad de articulación entre la Jurisdicción Especial Indígena y la JEP; la intervención limitada de la Procuraduría General de la Nación.
} 
incumplimiento de esas condiciones, estas personas se someten a la pérdida de cualquier tipo de beneficio o tratamiento especial.

Teniendo como sustento los anteriores criterios judiciales expuestos, las normas constitucionales y legales que crean y desarrollan el SIVJRNR parten del reconocimiento de la paz como un principio orientador del sistema y derecho "síntesis". Estas normas reafirman la interconexión entre cada uno de los componentes del sistema, esto es, $\operatorname{verdad}^{45}$, justicia, reparación y no repetición, con lo cual se confirma la integralidad del esquema transicional dispuesto.

El enfoque deja de girar exclusivamente en torno a medidas de tipo punitivo, esto es, el juicio penal y la pena tradicional. Si bien estas medidas se contemplan, son solo parte de un abanico de posibilidades para la garantía de los diversos derechos de las víctimas, para la aspiración de conseguir una paz estable y duradera, y para generar plena seguridad jurídica a quienes se sometan al sistema. Tal condición de integralidad en las medidas de transición venía siendo reclamada por la Corte Constitucional desde la revisión de la Ley 975 del 2005.

El proyecto de Ley Estatutaria recapitula el concepto judicial de "Régimen de Condicionalidad" compuesto por: la obligación de aportar verdad plena; contribuir a la reparación de las víctimas; garantizar la no repetición; la dejación de las armas; contribuir al proceso de reincorporación a la vida civil y la entrega de menores de edad ${ }^{46}$. Es así como el incumplimiento intencional, verificado en cada caso por la JEP, de cualquiera de tales condiciones o de las sanciones impuestas conlleva a la pérdida de todos los tratamientos especiales, beneficios, renuncias, derechos y garantías.

Como criterio interpretativo, se establece el respeto al DIH y la garantía de los DDHH, además se ratifica el deber del Estado de investigar, esclarecer, perseguir y sancionar las graves violaciones a los DDHH e infracciones al DIH. No obstante, en relación con la

45 A propósito de la garantía del derecho a la verdad, la Corte Constitucional en Comunicado de Prensa N. ${ }^{\circ} 11$ del 21 de marzo del 2018 anunció la Sentencia C-017 del 2018, que declaró exequible, salvo ciertos apartes, el Decreto Ley 588 del 2017 que organizó la Comisión para el esclarecimiento de la verdad, la convivencia y la no repetición. Indicó la Corte que, en el análisis de constitucionalidad del articulado, la sala plena tomó en consideración el margen de configuración del legislador extraordinario para la paz, en particular, teniendo en cuenta que la regulación analizada pretende garantizar el derecho a la verdad e implementar contenidos esenciales del SIVJRNR, previstos en el Acuerdo Final.

46 Las tres últimas condiciones son aplicables a los excombatientes de las FARC. 
medida razonable de cumplimiento de dicho deber, se faculta al Estado, en el marco del principio de soberanía, para apreciar y evaluar la complejidad, duración y la gravedad del conflicto armado, y para, a partir de allí, diseñar y adoptar los mecanismos de justicia para alcanzar la paz. Igualmente, se reconocen las limitaciones fácticas para el cumplimiento maximalista de la obligación estatal, por lo cual se promueve el deber de asegurar la verdad, justicia, reparación y medidas de no repetición a través de los medios razonables, dentro del alcance estatal y con base en la debida diligencia respecto del deber de justicia.

Por su parte, se establece la selección como principio de la JEP. En consecuencia, el trabajo institucional de la JEP se enmarca en estrategias de priorización y de centralización del ejercicio de la acción penal a partir de la (i) gravedad y representatividad de los crímenes y (ii) el grado de participación y responsabilidad en los mismos. Es así como, frente a los hechos y las personas que no sean objeto de selección para investigación y judicialización, resulta posible aplicar la figura de la renuncia condicionada de la acción penal. Se hace la salvedad, sin embargo, de algunas excepciones y precisiones que se detallan más adelante.

El proyecto de Ley Estatutaria de la JEP establece, de manera no taxativa, los siguientes criterios de selección:

a. Gravedad de los hechos: grado de afectación de derechos fundamentales individuales y colectivos; modalidad de la comisión de los hechos en términos de violencia y sistematicidad.

b. Representatividad: efectos de la investigación y judicialización de los hechos; capacidad de ilustración del modus operandi o de prácticas o patrones criminales de los hechos.

En relación con la gravedad delictual, la sentencia C-579 del 2013 concluyó que las categorías de genocidio, crímenes de lesa humanidad y de guerra cometidos de manera sistemática ${ }^{47}$ subsumen las graves violaciones a 
los DDHH cometidas en el marco de un conflicto armado. El proyecto conciliado de Ley Estatutaria de la JEP dispone que tales categorías criminales no son objeto de amnistía, ni renuncia al ejercicio de la acción penal o beneficios equivalentes. Se incluyen igualmente los delitos mencionados en el parágrafo artículo 23 de la Ley 1820 del $2016^{48}$, como la toma de rehenes u otra privación grave de la libertad; la tortura; las ejecuciones extrajudiciales; la desaparición forzada; el acceso carnal violento y otras formas de violencia sexual; sustracción de menores; desplazamiento forzado; el reclutamiento de menores, de conformidad con lo establecido en el Estatuto Roma.

c. Características de los responsables: participación activa y determinante en la comisión de los crímenes de competencia de la JEP o prueba de su autoría o participación en los hechos concretos. La Corte, en la sentencia C-579 del 2013, estima que la calidad de máximos responsables de las categorías criminales antedichas se establece con respecto al rol esencial en la organización criminal para la comisión de cada delito. Se asume una perspectiva amplia con respecto a dicho rol, y las disposiciones normativas de la JEP hablan del concepto de "participación activa y determinante".

Si bien el proyecto de Ley Estatutaria de la JEP prohíbe que las conductas establecidas en el parágrafo del artículo 23 de la Ley 1820 del 2016 sean objeto de renuncia al ejercicio de la acción penal, esto se contrapone con la función de la Sala de Definición de Situaciones Jurídicas ${ }^{49}$, destinada a definir la situación de quienes no han tenido una participación determinante en los casos más graves y representativos. Esta función se da en particular con respecto a las conductas a las que se refiere el artículo 23

48 Por medio de la cual se dictan disposiciones sobre amnistía, indulto y tratamientos penales especiales y otras disposiciones. La Ley parte de la reafirmación de artículo 6.5 del Protocolo Adicional in de las Convenciones de Ginebra de 1949, es decir, de la prescripción de aplicar la amnistía en la mayor medida de lo posible. 49 Literal H, artículo 84 del proyecto conciliado de Ley Estatutaria 008 del 2017Senado y 016 del 2017-Cámara "Estatutaria de la Administración de Justicia en la Jurisdicción Especial para la Paz”. 
de la Ley 1820 del 2016, el cual abre la posibilidad, para estos casos, de renunciar a la acción penal o terminar anticipadamente el proceso, posibilidad que se reafirma en el proyecto de Ley Estatutaria en una de las disposiciones relativas a las sanciones del sistema. Esta aparente situación de contradicción deberá ser aclarada en sede de control constitucional.

d. Características diferenciales de las víctimas: condiciones de vulnerabilidad o necesidad de adoptar medidas diferenciales de protección derivadas de patrones históricos, sociales y culturales de discriminación que se han identificado a partir de aspectos como el origen étnico, el género, la edad, la condición de discapacidad, la orientación sexual y la identidad de género, o el rol social de la víctima.

e. Disponibilidad probatoria: calidad y cantidad de las pruebas disponibles, las requeridas para probar el hecho y su dificultad para conseguirlas.

Se reconoce que la pena tradicional dotada de un fin primordialmente de represión y retribución no resulta la más apropiada en un escenario especial de tránsito hacia la paz, por lo cual se impulsa una función restaurativa y reparadora. Se genera un esquema de sanciones especiales, incluyendo sanciones propias eminentemente reparadoras con un contenido de restricción de derechos y libertades de 5 a 8 años bajo unas condiciones orientadoras: no son equiparables a una pena de cárcel o prisión, pero sí son objeto de monitoreo, vigilancia y control, con posibilidad de descuento de la sanción. Las sanciones propias del sistema se aplican, de manera condicional, a las personas que, habiendo participado de manera activa y determinante en los crímenes de mayor gravedad, reconozcan verdad total y responsabilidad en una etapa procesal temprana. Por su parte, las sanciones alternativas cuentan ya con una finalidad principalmente retributiva acudiendo a la pena privativa de la libertad (prisión) de 5 a 8 años y se aplican a las personas que, habiendo participado de manera activa y determinante en los crímenes de mayor gravedad, reconozcan verdad total y responsabilidad en una etapa procesal tardía. 
Los límites temporales establecidos para las sanciones propias y alternativas se pueden reducir entre 2 y 5 años para las personas que, a pesar de haber participado en la comisión de graves crímenes contra los DDHH y el DIH, no se consideran máximos responsables al no haber tenido una participación activa y determinante, salvo para el caso en que la Sala de Definición de Situaciones Jurídicas decida renunciar a la acción penal o terminar anticipadamente el proceso. Finalmente, las sanciones penales ordinarias de privación efectiva de la libertad de 15 a 20 años, para los más graves crímenes, se aplican a las personas que no hayan reconocido verdad y responsabilidad, teniendo como beneficio la posibilidad de redención de pena por trabajo, capacitación o estudio.

Todo lo anterior refleja la trascendencia que el SIVJRNR tiene para la construcción, sostenibilidad y seguridad del proceso hacia la paz, partiendo de la pretensión de liberar las tensiones que, en contextos de transición, se hacen latentes entre las exigencias internacionales de justicia, el reconocimiento y garantía de otros derechos de las víctimas, las aspiraciones de seguridad jurídica para quienes se acojan al sistema y las aspiraciones de estabilización de orden social.

\section{Apreciaciones finales}

A partir de la consolidación del bloque de constitucionalidad, el Estado colombiano ha adquirido varios compromisos internacionales. Uno de ellos referido a la garantía de justicia frente a graves violaciones de DDHH y del DIH. Estos deberes de garantía, por su carácter abierto, son propensos a generar debates en torno a su real contenido, alcance y limitaciones. En un camino de doble vía, tanto las iniciativas normativas como la jurisprudencia constitucional se han visto influenciadas a la hora de ir construyendo un referente de justicia transicional para Colombia que logre alcanzar el umbral mínimo en relación con tales compromisos.

No obstante, la tarea no ha sido fácil, ni puede darse por concluida. La evolución accidentada del deber internacional de justicia en contextos transicionales en Colombia así lo demuestra. A raíz de las precisiones jurisprudenciales en torno a las medidas adoptadas en la Ley de Justicia y Paz, se abre la posibilidad de 
adoptar modelos integrales de justicia transicional conscientes de las restricciones propias de las situaciones de excepcionalidad. Solo después de un período de fracasos institucionales al implementar la Ley 975 del 2005, y de la inestabilidad jurisprudencial generada en ese período, el tema adquiere la fuerza que las posibilidades del acuerdo con la guerrilla de las FARC le otorgan.

Revisado el marco jurídico vigente, es claro que se renuncia a la idea de implantar posiciones maximalistas. Más bien, se afianza la idea de entender el deber estatal de justicia en caso de grave criminalidad como un principio a ser realizado en la mayor medida posible, como un principio ponderable ante tensiones con otros valores o derechos, y más aún ante situaciones excepcionales de tránsito hacia la paz, a través del diseño e implementación de un esquema integral de justicia transicional.

No obstante, y a pesar del innegable avance en el desarrollo institucional del actual esquema de justicia transicional en Colombia, sin haber sido el tema central de análisis de este escrito, vale la pena mencionar ciertos aspectos sobre los que recaen duras críticas y persisten en el debate actual ${ }^{50}$ :

La regulación diferenciada de la responsabilidad de mando para los miembros de la fuerza pública dispuesta en el artículo transitorio 24 del Acto Legislativo 01 del 2017. Al sentir de algunos, esta regulación va en contravía del Derecho Internacional Consuetudinario y del Estatuto de Roma, pues establece una serie de condiciones concurrentes a efectos de determinar la existencia de control efectivo del superior con respecto a la conducta de su subordinado.

La sistematicidad de los graves crímenes de guerra. En efecto, la misma Corte Constitucional en la sentencia C-579 del 2013, acepta la tesis según la cual tales crímenes deben ser entendidos como infracción al DIH cometida de forma sistemática. Esta calificación es criticada al sostener que, aun cuando no sea sistemático, el crimen de guerra sigue siendo una grave infracción al DiH. Así las cosas, el deber de justicia se estaría limitando más allá de sus límites razonables en contextos de transición, pues

50 Varias de ellas se reflejan en el escrito de Amicus Curiae de la fiscal de la Corte Penal Internacional sobre la Jurisdicción Especial para la Paz ante la Corte Constitucional de la República de Colombia, de 18 de octubre del 2017. Referencia: RPZ-0000001 y RPZ-003. 
permitiría incluso la aplicación de la amnistía o renuncia a la acción penal con respecto a crímenes de guerra de los cuales se descarte el elemento de sistematicidad. No obstante, resulta pertinente mencionar que en el reciente comunicado de prensa N. ${ }^{\circ} 8$ del 1 de marzo del 2018 la Corte Constitucional anunció la sentencia C-007 del 2018, mediante la cual se realiza el control automático y definitivo de la Ley 1820 del 2016 -con la que se implementó lo relacionado con la amnistía, el indulto y tratamientos penales especiales-. En esta ocasión, frente a la expresión "se entenderá por 'grave crimen de guerra' toda infracción al Derecho Internacional Humanitario cometida de forma sistemática”, la Corte declaró inexequibles las expresiones "graves" y "de manera sistemática”, indicando que ellas "se apart[a]n de conceptos ya decantados en el derecho internacional humanitario y el derecho penal internacional, $y$, en consecuencia, introducen incertidumbre en un ámbito que debe dar certeza a víctimas y perpetradores" (CC, 2018). Pareciere entonces que con tal decisión se zanja en cierta medida la discusión sobre este punto. Sin embargo, será oportuno esperar a conocer el fallo en su integridad.

Ambigüedad en torno a la posibilidad de renunciar a la acción penal frente a las personas que no han tenido una participación determinante en los crímenes más graves y representativos no amnistiables. Si bien la Corte Constitucional admite en la sentencia C-579 del 2013 tal posibilidad en el marco de la estrategia de selección, el proyecto de Ley Estatutaria de la JEP en principio parece prohibirla, entrando en aparente contradicción con artículos posteriores.

La fuerza y legitimidad de las sanciones del SIVJRNR sigue siendo un tema polémico, en particular en torno a las sanciones propias del sistema. Se discute aun la efectividad de la restricción de derechos y libertades de tales sanciones, teniendo en cuenta unas condiciones de restricción y un esquema de monitoreo, vigilancia y control aparentemente flexibles en exceso.

Los anteriores aspectos, y otros no mencionados, podrían resultar problemáticos en la implementación del SIVJRNR, así como en su evaluación y seguimiento por la comunidad e instancias internacionales. Muchos de estos aspectos serán, con seguridad, objeto de abordaje o pronunciamiento en el texto completo de la 
sentencia C-674 del 2017 o en el fallo de revisión constitucional del proyecto de Ley Estatutaria de la JeP.

\section{Referencias}

Barbosa, F. (2017). ¿justicia transicional o impunidad? Bogotá: Ediciones B Colombia S. A.

Centro Internacional para la Justicia Transicional (2009). ¿Qué es la Justicia Transicional?. Centro Internacional para la Justicia Transicional.

Congreso de Colombia. (25 de julio del 2005). Por la cual se dictan disposiciones para la reincorporación de miembros de grupos armados organizados al margen de la ley, que contribuyan de manera efectiva a la consecución de la paz nacional y se dictan otras disposiciones para acuerdos humanitarios. [Ley 975 del 2005]. DO: 45980.

Congreso de Colombia. (9 de julio del 2009). Por medio de la cual se reforma la Ley 906 del 2004 en lo relacionado con el principio de oportunidad. [Ley 1312 del 2009]. DO: 47405.

Congreso de Colombia. (29 de diciembre del 2010). Por la cual se dictan disposiciones de justicia transicional que garanticen verdad, justicia y reparación a las víctimas de desmovilizados de grupos organizados al margen de la ley, se conceden beneficios jurídicos y se dictan otras disposiciones. [Ley 1424 del 2010]. DO: 47937.

Congreso de Colombia. (10 de junio del 2011). Por la cual se dictan medidas de atención, asistencia y reparación integral a las víctimas del conflicto armado interno y se dictan otras disposiciones. [Ley 1448 del 2011]. DO: 48096.

Congreso de Colombia. (31 de julio del 2012). Por medio del cual se establecen instrumentos jurídicos de justicia transicional en el marco del artículo 22 de la Constitución Política y se dictan otras disposiciones. [Acto legislativo 01 del 2012].

Congreso de Colombia. (4 de abril del 2017). Por medio del cual se crea un título de disposiciones transitorias de la constitución para la terminación del conflicto armado y la construcción de una paz estable y duradera y se dictan otras disposiciones. [Acto legislativo $01 \mathrm{del}$ 2017].

Congreso de Colombia, Informe de Conciliación al Proyecto de Ley Estatutaria 008 del 2017-Senado y 016 del 2017-Cámara "Estatutaria de la Administración de Justicia en la Jurisdicción Especial para la Paz" - Procedimiento Legislativo Especial.

Corte Constitucional. (03 de mayo de 1993) Sentencia C-171. [MP Vladimiro Naranjo Mesa]. 
Corte Constitucional. (18 de mayo del 2006). Sentencia C-370. [MP Álvaro Tafur Galvis y otros].

Corte Constitucional. (25 de julio del 2006). Sentencia C-575. [MP Álvaro Tafur Galvis].

Corte Constitucional. (23 de noviembre del 2010). Sentencia C-936. [MP Luis Ernesto Vargas].

Corte Constitucional. (13 de octubre del 2011). Sentencia C-711. [MP Nilson Pinilla Pinilla].

Corte Constitucional. (13 de septiembre del 2012). Sentencia C-715. [MP Luis Ernesto Vargas].

Corte Constitucional. (24 de abril del 2013). Sentencia SU-254 [MP Luis Ernesto Vargas]

Corte Constitucional. (28 de agosto del 2013). Sentencia C-579. [MP Jorge I. Pretelt C].

Corte Constitucional. (1 de febrero del 2017). Sentencia C-042. [MP Aquiles Arrieta G.]

Corte Constitucional. Comunicado de Prensa 55 de noviembre 14 del 2017. Expediente RPZ-003-Sentencia C-674 del 2017. [MP Luis Guillermo Guerrero Pérez].

Corte Constitucional. Comunicado de Prensa 01 de marzo 21 del 2018. Expediente RPZ-001-Sentencia C-007 del 2018. [MP Diana Fajardo Rivera].

Corte Constitucional. Comunicado de Prensa 11 de marzo 21 del 2018. Expediente RDL-009-Sentencia C-017 del 2018. [MP Diana Fajardo Rivera].

Corte Interamericana de Derechos Humanos. (25 de octubre del 2012). Sentencia caso El Mozote. [Voto concurrente Juez Diego GarcíaSayán].

Corte Penal Internacional. (18 de octubre del 2017). Escrito de Amicus Curiae de la Fiscal de la Corte Penal Internacional sobre la Jurisdicción Espcial para la Paz. La Haya.

Gómez, G. I. (2014). Justicia transicional en disputa. Una perspectiva constructivista sobre las luchas por la verdad, la justicia y la reparación en Colombia. Medellín: Universidad de Antioquia.

Ibáñez, J. E. (2017). Justicia transicional y comisiones de la verdad. Bogotá: Instituto Berg Oceana Aufklarung.

López, C. (2012). Selección y priorización de delitos como estrategia de investigación en la justicia transicional. Revista Facultad de Derecho y Ciencias Políticas, 42(117), 515-579.

Olsen, T. D., Payne, L. A., y Reiter, A. G. (2016). Justicia transicional en equilibrio: Comparación de procesos, sopeso de su eficacia. Bogotá: Pontificia Universidad Javeriana. 
Organización de las Naciones Unidas. [ONU]. (2011). El Estado de derecho y la justicia de transición en las sociedades que sufren o han sufrido conflictos. ONU: Informe del Secretario General.

Organización de las Naciones Unidas. [ONU]. (2014). Justicia transicional y derechos económicos, sociales y culturales. ONU: Oficina del Alto Comisionado para los Derechos Humanos (ACNUDH).

Rettberg, A. (2005). Reflexiones introductorias sobre la relación entre construcción de paz y justicia transicional. En A. Rettberg (ed.), Entre el perdón y el paredón: Preguntas y dilemas de la justicia transicional (pp. 1-17). Bogotá: Centro Internacional de Investigaciones para el Desarrollo y Universidad de los Andes.

Torres, A. (2015). Reparando las amnistias en procesos transicionales. Bogotá: Publicaciones Universidad Externado de Colombia.

Uprimny, R., Saffon, M., Botero, C., y Restrepo , E. (2006). ¿.Justicia transicional sin transición? Verdad, justicia y reparación para Colombia. Bogotá: Dejusticia.

Uprimny, R., Sánchez, L. M., y Sánchez, N. (2014). Justicia para la paz. Bogotá: Dejusticia. 